\title{
Linking introductory astronomy students' basic science knowledge, beliefs, attitudes, sources of information, and information literacy
}

\author{
Sanlyn R. Buxner, ${ }^{1, *}$ Chris D. Impey, ${ }^{2}$ James Romine, $^{3}$ and Megan Nieberding ${ }^{4}$ \\ ${ }^{1}$ Department of Teaching, Learning and Sociocultural Studies, \\ University of Arizona, Tucson, Arizona 85721, USA \\ ${ }^{2}$ Department of Astronomy, University of Arizona, Tucson, Arizona 85721, USA \\ ${ }^{3}$ Independent, Phoenix, Arizona 85203, USA \\ ${ }^{4}$ Department of Physics, Ohio State University, Columbus, Ohio 43210, USA
}

(Received 16 May 2017; published 15 June 2018)

\begin{abstract}
[This paper is part of the Focused Collection on Astronomy Education Research.] We report on a study of almost 13000 undergraduate students enrolled in introductory astronomy courses at the University of Arizona. From 1989 to 2016, students completed a basic science knowledge, beliefs, and attitudes survey. From 2014 to 2016, a subset of the sample completed an additional survey that probed their overall interest in science and astronomy, where they reported getting information about science, and their judgment of those sources. Our sample of mostly nonscience major students outperformed the general public on basic science knowledge questions during the time of the study. Additionally, there was very little change over the range of time of the study in students' basic science knowledge whose scores averaged around 79\% correct over the 27 years. Students' self-reported demographic information and beliefs and attitudes in science and technology accounted for only $11 \%$ of the variance in their science knowledge scores and there was no systematic pattern between where students reported getting their information about science and their basic science knowledge. Despite this, there was a relationship between how students rated the reliability of sources and their science knowledge. Our findings support that introductory astronomy courses are opportunities to improve students' attitudes towards science and ability to evaluate scientific information. Although this group of students' basic science knowledge and attitudes remained relatively unchanged over 27 years there was a measurable relationship between students' beliefs and attitudes, interest, science knowledge, and information literacy.
\end{abstract}

DOI: 10.1103/PhysRevPhysEducRes.14.010142

\section{INTRODUCTION}

For many nonscience major undergraduate students, introductory science courses such as Introductory Astronomy (e.g., Astro 101) are the last formal exposure to science course work they will have [1,2]. Increasing students' basic science knowledge and skills to use scientific information to make informed decisions is an ongoing concern for many college instructors and policy makers [3-6]. Across the education spectrum, educators argue that students should be trained in the ways that science is done [7] (recently reflected in the scientific practices of the Next Generation Science Standards [8]) as well as focus on educating students to be well-informed consumers and

\footnotetext{
*buxner@email.arizona.edu

Published by the American Physical Society under the terms of the Creative Commons Attribution 4.0 International license. Further distribution of this work must maintain attribution to the author(s) and the published article's title, journal citation, and DOI.
}

citizens who have basic scientific and information literacy $[4,6,9]$. Although these are not mutually exclusive goals, there is a debate about which is more important, which drives a discussion about focus and resource allocation in science courses [10-12]. To achieve either goal, educators often agree that basic science knowledge is an important foundation to help students gain an understanding of how science is done and how the world works $[4,6,8,13,14]$. This discussion encompasses $\mathrm{K}-12$ education, college education, and lifelong learning $[6,9,10,13,14]$.

Additionally, educators agree that basic information literacy is a foundational skill for student success in a variety of fields [15-17]. Thus, a foundation of science knowledge as well as the ability to evaluate sources of scientific knowledge are critical pieces to make students more educated consumers and citizens, regardless of their future professions. Although the exact definition of scientific literacy is under debate and often poorly defined, having a basic knowledge of science, understanding how science works, and the ability to assess science knowledge for decision making are often key aspects $[6,18]$. This philosophy was integrated into the 2000 and 
2003 Programme for International Student Assessments (PISA) which defined scientific literacy as "(the capacity to use scientific knowledge, to identify questions and to draw evidence-based conclusions in order to understand and help make decisions about the natural world...)" (p. 60) [19,20].

Introductory college nonmajor astronomy courses pose several interesting opportunities for both researchers and educators. They are opportunities to assess students who have completed a variety of $\mathrm{K}-12$ innovations in teaching, to assess future consumers of science, and to influence the science knowledge and interest of students one last time in their college career. Astronomy 101 courses are popular elective courses that attract a wide range of students and thus provide a unique opportunity to affect students from a variety of nonscience disciplines who take these courses. The students who take introductory astronomy courses as nonmajors represent a wide range of society who are well educated but may not enter a science or technical careers [21]. These courses often recruit students who are averse to math and looking to fulfill their general education science requirements. Many introductory astronomy educators consider themselves not only instructors of astronomy content, but also educators of general science education [2]. These courses also represent opportunities for instructors to discuss issues related to science in general and tackle more general issues such as scientific literacy, interest in science, information literacy, and support for science of future citizens and voters.

In this study, students in introductory astronomy courses at the University of Arizona were surveyed from 1989 to 2016. During those 27 years, a data set of almost 13000 student responses were collected. Data collection leveraged large enrollment introductory astronomy courses at the university to obtain a snapshot of what students know and think about science at different points in their college career. Students' basic science knowledge, beliefs, and attitudes are important to characterize for all introductory science courses, including astronomy, so that instructors have a snapshot of what students know and believe about science. In addition, a new survey was added in 2011 that contained questions to probe students' general interest in science, where students get their information about science, and their judgment of the reliability of that information. This study presents students' basic science knowledge, attitudes and beliefs towards science and technology, interest in science, sources of scientific knowledge, and information literacy as well as the relationships between each of these.

\section{A. Background}

Research of citizens' understandings of science inquiry began in 1957 by the National Association of Science Writers, who interviewed adults in the United States about their interest in and understanding of science and technology [22]. In 1978, the National Science Foundation (NSF) commissioned Jon Miller and Kenneth Prewitt to lead an effort to measure the "public understanding of, and attitudes toward, science and technology" (p. 275) [14]. That project resulted in ongoing reports documenting the public's interest and knowledge in science and technology as part of the Science and Engineering Indicators report series that is published by the National Science Board (NSB) every two years. The latest report was published in 2016 [23]. As described in the most recent report, a set of factual science questions were added to the project in the late 1980s and remain a core set of questions to understand trends in U.S. adults' knowledge of science. These items represent only one piece of science knowledge but are indicators of basic science knowledge that would be needed to understand a newspaper science section [14]. Although it is agreed knowledge of science facts is only one way to assess science knowledge, ongoing national and international surveys continue to use basic science knowledge questions developed and used by Miller and Prewitt for the NSB project in the 1980s [23]. Examples include a survey conducted by the Pew Research Center for People and the Press [24] in 2009 and a relatively recent survey by the Pew Research Center and Smithsonian Magazine [25] in which several of the same science knowledge questions from NSB project were included, in addition to questions probing understandings of current issues. Studies of students' interest in science and science knowledge have shown a positive relationship between their interest in science and their performance on science knowledge measures [26,27]. Additionally, attitudes towards science and scientific knowledge are both positively correlated with public understanding of science [28] although only weakly in the case of science knowledge.

Within the larger science education context, there exists a tension between preparing students to engage in science as practitioners, which requires preparation of scientific and technical knowledge and skills (often referred to as science literacy), and preparing students to exist in a scientifically literate society which requires preparing them in scientific ways of knowing and critical thinking skills for decision making (often referred to as scientific literacy) [6]. Although most educators and policy makers agree that both are part of the larger landscape of student education, there is a tension around how time and resources should be spent in training students towards the goal of one over the other [10-12]. Thus, the decision to prepare students to be science literate or scientifically literate depends on the overall goals of the teacher or educational institution [10]. Although there remains a debate, there is a vocal contingent of educators that agree that the purpose of nonscience major science courses is increasing students' scientific literacy [29-32].

An ongoing difficulty of the conversation is that there is no broad agreement on the definition of scientific literacy, although it is generally agreed that is it is important for 
citizens to be scientifically literate to make informed decisions in everyday life [5]. Miller [13,14] has argued that to be scientifically literate one must have both a basic vocabulary of scientific terms and constructs and a general understanding of scientific inquiry. For example, this level of scientific literacy could be defined as having enough knowledge to be able to "read and comprehend the Tuesday science section of The New York Times (p. 274) [14]. Others have defined scientific literacy as encompassing a broad range of knowledge and skills including knowledge of content, distinguishing science from nonscience, understanding the applications of science, ability to think scientifically and to use scientific knowledge in problem solving, understanding the nature of science, knowledge of risks and benefits of science, and ability to have meaningful discourse of scientific issues $[33,34]$. Although there is contention about all of the components of scientific literacy, a core set of knowledge and ability to use and evaluate information are present in most definitions $[6,20]$.

Because of the varying definitions of scientific literacy, there have been several ways that scientific literacy has been assessed. Examples include the work of Miller and colleagues who have continually assessed adults' knowledge of basic scientific knowledge, contemporary scientific issues, interest in science, and support for science, comparing responses across countries [14]. The Test of Basic Scientific Literacy was developed for high school graduates in South Africa and based on the work of Miller to assess students' understanding of "(the nature of science, science content knowledge, and the impact of science and technology on society)" (p. 331) [35]. The Test of Scientific Literacy Skills was developed as a robust survey of students' scientific literacy skills related to "recognizing and analyzing the use of methods of inquiry that lead to scientific knowledge and the ability to organize, analyze, and interpret quantitative data and scientific information" (p. 364) for use in determining the impact of curriculum reform on students' scientific literacy [36]. The Programme for International Student Assessments (PISA) has continued to refine its definition of scientific literacy and assessment, the latest version was in 2015 which included content knowledge, procedural knowledge and epistemic knowledge. The 2015 definition of scientific literacy was broadened to include, "the ability to engage with science-related issues, and with the ideas of science, as a reflective citizen. A scientifically literate person, therefore, is willing to engage in reasoned discourse about science and technology which requires the competencies to: 1. Explain phenomena scientifically 2. Evaluate and design scientific enquiry, and 3. Interpret data and evidence scientifically" (p. 7) [20]. As definitions of scientific literacy continue to be refined, so do the ways developed to assess it. As the skills deemed important to be a productive member of society are continually defined, these skills are integrated into the development of ongoing assessments.
Information literacy is not only a critical component of lifelong decision making in helping people identify appropriate sources of information and evaluate the quality of information from each source, it is arguably an important part of scientific literacy $[9,16,17]$. As defined by the Association of American Colleges and Universities, information literacy is "the ability to know when there is a need for information, to be able to identify, locate, evaluate, and effectively and responsibly use and share that information for the problem at hand" [37]. With the proliferation of online resources, helping students evaluate content is increasingly important as well as understanding where students get their information about science to support instruction. Thus, information literacy and scientific literacy are arguably important in all science courses, making science courses for nonscience majors, perhaps their last science course, opportunities for instructors to help build non-science students' information literacy skills related to scientific topics. [38,39].

This study brings together several areas of interest that are important to the discussion of scientific literacy, including basic science knowledge, attitudes towards science and technology, students' own interest in science, where students report getting information about science, and their judgment of sources of science information. The study draws on the basic science knowledge items used by the National Science Board to study a particular population: undergraduate nonmajor science students in introductory astronomy courses at a single university. Studying this population allows a closer look at the influence of other factors such as college courses and other student demographics on their basic science knowledge as well as their attitudes towards science and technology. In addition, this study investigates how students' attitudes towards science and technology interact with students' basic science knowledge to better understand the relationship. Lastly, the study looks at how these outcomes are related to where students report getting information about science and their judgement of those sources. Taken together, these different assessments are giving insight into the relationship between students' knowledge, interests, sources of knowledge, attitudes, and beliefs.

\section{B. Research questions}

This work builds upon several other studies published in recent year about introductory astronomy college students' science knowledge and attitudes [40-42]. Our previous work has shown that there has been little change in students' science knowledge responses over time and that students' demographic information explains a minimal amount of the variance in their knowledge scores $[40,42]$. However, other work has also shown that (a) introductory astronomy courses are popular among a broad range of students [1,2,21], (b) the number of college science courses has been shown to be a strong predictor 
of civic scientific literacy, defined as having "(1) a basic vocabulary of scientific terms and constructs; and (2) a general understanding of the nature of scientific inquiry" (p. 273) in U.S. adults [14], and (c) a positive relationship exists between interest and attitudes and individuals' understanding in science [26-28]. In addition, there is ongoing interest in building students' scientific literacy comprised of multiple facets, including scientific knowledge and students' ability to locate and use information (information literacy) $[9,16,17]$. This study of introductory astronomy students investigates all these aspects together: the level of, and interactions between basic science knowledge, attitudes and beliefs, interests; sources of knowledge and ability to judge sources of information to give insights into these students with implications for the context of the introductory astronomy course. The research questions that guided this study were as follows:

(1) How do introductory astronomy college students' responses to basic science knowledge questions compare to nationally reported responses?

(2) How are introductory astronomy students' characteristics, beliefs, and attitudes related to their science knowledge scores?

(3) What is the relationship between introductory astronomy students' interest in science, their career plans, and how useful they believe science will be to their future career?

(4) What is the relationship between students' sources for science information and their science knowledge?

(5) What are the relationships between introductory astronomy students' judgments of the reliability of sources of information and their science knowledge?

\section{METHODS}

\section{A. Research context}

This study was conducted in the Department of Astronomy at the University of Arizona, a large LandGrant, Research I institution. The University of Arizona currently serves a total of 43625 students (34 072 undergraduate and 7946 graduate) [43]. These numbers have grown from serving 31843 students in 1989 (26626 undergraduates and 5216 graduate). Students at the University of Arizona score around the 60th percentile of the national distribution of SAT scores and thus represent students at many large public universities.

\section{B. Data collection}

Data for this study were collected through two surveys of students between 1989 and 2016. The surveys were administered by instructors in their own classrooms either on paper or, in recent years, online. Ninety-eight percent of surveys completed were included in the study; those excluded either had a large portion of missing data or showed systematic pattern responses. The first survey, Science Knowledge, Attitudes and Beliefs Survey, included questions that probed students' basic knowledge, attitudes, and beliefs about science. The second survey, Interest and Sources of Information in Science, included questions about where students get their information about science, their rating of the quality of those sources, their interest in science, and their self-rating of their own knowledge. These surveys were administered in introductory astronomy courses for nonmajors at the University of Arizona at the beginning of each course. The first survey has been given almost every year to students since 1989 . The second survey began data collection in 2012 as a stand-alone survey. The surveys were combined and administered together from 2014 to 2016.

\section{Instrument development}

\section{Science knowledge, beliefs, and attitudes survey}

The first survey included a set of forced-choice (true or false) and open-ended items assessing basic science knowledge, derived from the National Science Board Science and Engineering Indicators [44] and work by Miller [45], as well as a series of Likert-scale questions probing beliefs and attitudes about science and technology. In addition to the science knowledge, belief, and attitude questions, students were asked to report the number of college science courses they had completed, their year in school, gender, major, and GPA. After a round of interviews with undergraduate students in 2011, three of the true or false knowledge items were eliminated in the final analysis due to lack of question clarity. The survey results reported here include 14 true or false questions about basic science knowledge along with one open-ended item asking students about their knowledge about what it means to study something scientifically. The survey also included 24 Likert-scale (from "strongly agree" to "strongly disagree") questions to assess students' attitudes and beliefs towards different topics in science and technology. After data collection, these items were analyzed and a final 16 items were binned into four categories or factors for use in subsequent analyses (belief in aliens and life beyond earth, positive attitudes towards science and technology, faithbased beliefs, and belief in unscientific phenomena) using a three-stage approach.

The first step was to have six experienced science experts and experienced science educators bin the questions into categories. Table I shows the initial five categories determined by the expert group who had a strong degree of agreement in the categorization (92\%). Items that are labeled as "reversed" in Table I refer to statements that are negative in meaning to the overall category. Thus, during analyses, these items had their scales reversed for inclusion in the category.

The next step to categorize these items was using an exploratory factor analysis. A random sample of 3000 
TABLE I. Initial belief and attitude categories resulting from expert categorization.

Category 1: Belief in aliens and life beyond Earth

UFOs are real and should be investigated.

It is almost certain that there are intelligent lifeforms in other parts of the Universe.

Some ancient civilizations were visited by extraterrestrials.

We should make a concerted effort to search for life on other planets.

Category 2: Positive attitudes towards science and technology

Overall, the progress of science and technology has been beneficial to our civilization.

Nuclear power is an important energy source and its use should be expanded.

The government should strongly support the manned space program.

Genetic engineering is a good idea.

Pure science should be funded regardless of its lack of immediate benefit to society.

Science will come up with a way to dispose of toxic waste.

Computers will eventually be intelligent enough to think like humans. (reversed)

Technology has too much control over our lives. (reversed)

Category 3: Faith-based beliefs

The Biblical story of creation should be taught alongside evolution theory in our schools.

The Universe was created in an enormous explosion billions of years ago. (reversed)

Faith healing is a valid alternative to conventional medicine.

Category 4: Belief in unscientific phenomena

There are phenomena that physical science and the laws of nature cannot explain.

The positions of the planets have an influence on the events of everyday life.

Some people possess psychic powers.

Some numbers are especially lucky for some people.

Category 5: Ethical concerns

There are some circumstances when medical science should not be used to prolong life.

Scientists should take responsibility for the bad effects of their theories and inventions.

We should devote more of our money and scientific resources to repair damage done to the environment.

We should exert more control over the nuclear weapons developed by scientists.

Scientists should be allowed to do research that causes pain to animals, if it helps solve human health problems. (reversed)

response sets were subjected to an exploratory factor analysis using squared multiple correlations as prior communality estimates. The principle factor method was used to extract factors and this was followed by a varimax (orthogonal) rotation. A scree test suggested four meaningful factors that were empirically derived.

In interpreting the rotated factor pattern, an item was said to load on a given factor if the factor loading was 0.35 or greater for that factor, and was less than 0.35 for other factors [46]. Items that did not follow that pattern, either did not load strongly on any factor or loaded high on multiple factors, were discarded. Using these criteria, four items were found to load on the first factor, which we labeled "Belief in Aliens and Life Beyond Earth". These were the same items that were classified by the expert reviewers. Five of the original seven items loaded onto the second factor which we labeled "positive attitudes towards science and technology." Four items loaded onto the third factor which we labeled "faith-based beliefs;" it is notable that one of the items categorized by the expert reviewers as having been part of the "belief in unscientific phenomenon," ended up in this category. The other three items loaded onto the fourth factor, which we labeled "belief in unscientific phenomena." Items that were originally coded under ethical concerns were not included in the final model or subsequent analyses due to low factor loadings and cross loadings with other categories. Thus, although the topic of "ethical concerns" were of interest to the original study, the items were not of sufficient reliability to be included Table II below shows the factor loadings for each item.

The final step was to cross validate this model that included 16 items in four factors using a confirmatory factor analysis (CFA) testing to see how well our model accounted for the observed relationships in the data set. Another set of cases not used in the exploratory factor analysis $(n=3000)$ were used to test the quality of the model. The final model was set up with four latent factors with the items in the table above loading onto them. In determining the quality of a model using CFA, there is no one single measure that indicates the fit but rather a set of fit indices that researchers use as a barometer of overall fit [46]. The final fit of the model was acceptable for several indicators of fit. Values of fit for the model were $\mathrm{GFI}=0.96, \mathrm{AFGI}=0.92, \mathrm{CFI}=0.89, \mathrm{NFI}=0.88$, and $\mathrm{RMSR}=0.07$. For the first four indices, values closer to 1.0 indicates better fit of the model to the data, with a general rule of thumb of 0.90 being an indicator of good fit. For the RMSR, smaller values are used of evidence of good 
TABLE II. Salient factor loadings (above 0.35) for items retained in the model.

\begin{tabular}{lc}
\hline \hline Factor 1: Belief in aliens and life beyond Earth & Factor loading \\
\hline UFOs are real and should be investigated. & 0.76 \\
It is almost certain that there are intelligent lifeforms in other parts of the Universe. & 0.62 \\
Some ancient civilizations were visited by extraterrestrials. & 0.70 \\
We should make a concerted effort to search for life on other planets. & 0.46 \\
Factor 2: Positive attitudes towards science and technology & 0.43 \\
Overall, the progress of science and technology has been beneficial to our civilization. & 0.42 \\
The government should strongly support the manned space program. & 0.41 \\
Genetic engineering is a good idea. & 0.40 \\
Pure science should be funded regardless of its lack of immediate benefit to society. & 0.44 \\
Science will come up with a way to dispose of toxic waste. & 0.54 \\
Factor 3: Faith-based beliefs & 0.38 \\
The Biblical story of creation should be taught alongside evolution theory in our schools. & 0.47 \\
There are phenomena that physical science and the laws of nature cannot explain. \\
The Universe was created in an enormous explosion billions of years ago. (reversed) \\
Faith healing is a valid alternative to conventional medicine. & 0.38 \\
Factor 4: Belief in unscientific phenomena & 0.50 \\
The positions of the planets have an influence on the events of everyday life. & 0.37 \\
Some people possess psychic powers. & 0.55 \\
Some numbers are especially lucky for some people. &
\end{tabular}

fit. Responses to items within each factor are correlated, and this analysis is a quantitative way of seeing some of the contours of the "landscape" of student attitudes and beliefs.

\section{Interest and Sources of Information in Science Survey}

The second survey was developed in 2011 to investigate where students were getting information about science, their rating of the reliability of different sources of information, and their general interest in science. An initial survey was developed from previous work on where the public gets information about science [47]. Students were recruited to complete an open-ended pilot survey during 2012. The survey asked students basic questions about science, to describe what it means to study something scientifically, to rate their own interest in knowledge in science, to report where they obtain information about science, and to report what they believed to be the most and least reliable sources of science knowledge. A total of 650 students completed the initial survey and responses were analyzed to create forced choice responses for most of the survey questions. After analysis of the initial survey results, in the spring of 2013, we interviewed 29 students to gain insight into student responses to the survey described above as well as gain insight into how these students used information they gathered to make decisions in their daily lives. Before the interviews, students were asked to take an adapted version of the survey. During the interviews, students were asked about their specific responses on the survey. Interviews were audiotaped and investigators took field notes during the interviews. Interviews were used to validate survey questions and make changes to improve the quality of answer choices. All survey and interview data were transcribed for analysis. Reliability analysis was conducted for the components of the final survey and were all above 0.85 . An updated survey was administered in the fall of 2013 and spring 2014 and revised based on the field testing. Finally, this survey was given in combination with the first survey to students between 2014 and 2016.

\section{Analyses of survey items}

The forced-choice basic science knowledge questions on the first survey were scored as correct and incorrect and a simple basic science knowledge score was assigned to each student, from 0 to 14 . Additionally, nine items that directly overlapped with the National Science Board biannual reports and other science literacy surveys were used as a subgroup analysis. Descriptive statistics were used to obtain an overall look at students' responses to the science knowledge questions, reported below. In several cases, standard parametric procedures of group comparisons were used (independent $t$ tests and ANOVAs), reported below. These are not highlighted in the findings due to the large power created by such a large sample size. Thus, although all tests resulted in statistically significant differences, these results were interpreted cautiously and analyzed for practical significance, reported below.

To score students open-ended responses to the question, "what does it mean to study something scientifically?" students' responses were analyzed through open coding, which allowed codes to emerge from the data. Additionally, codes were extracted from existing literature on the nature of science [48]. Two education researchers independently coded responses, discussing themes and alternative 
explanations until a consistent set of codes was reached. Interrater reliability for this open-ended coding was analyzed using a random set of 1000 student responses and calculating Cohen's kappa in SPSS. There was strong agreement between the raters, $\kappa=0.812, p<0.05$.

In addition to thematic coding, responses were coded for complexity using the following rubric:

(0) Nonresponsive, off-target (e.g., I don't like science, this is boring).

(1) Responds to the question, but did not communicate a depth of knowledge of scientific study. (e.g., to observe phenomena to test, experiment, and prove).

(2) Response is on target, acceptable, and includes basic aspects of scientific study as well as more in-depth aspects, such as analysis or repetition (e.g., to study something scientifically you need to test, observe, and retest whatever it is. You would form a hypothesis based on your observations and continue to test it.).

(3) Response is on target, and combines several aspects of science making connections between those aspects and includes a discussion of evidence (e.g., one must form a testable hypothesis in regard to a phenomenon. Testing should be carried out to reduce bias and isolate variables. All tests should be repeatable and corroborated by other scientists.).

(4) Exemplary response that is not only on target but describes multiple aspects of science and connects those aspects in a meaningful way.

Two education researchers coded the first 100 responses together to calibrate different levels of responses and comparing coding. Interrater reliability for this coding was analyzed using a random set of 1000 student responses and calculating a Spearman's rank order correlation, due to the ordinal nature of the data. Overall, there was significant strong relationship between the two coders, $r_{s}(1000)=0.889, p<0.05$.

For the Likert-scale attitude and belief questions, a factor score was created for each of the four categories by taking an average of students' responses to each item within the factor. Secondary data analysis, including multiple regression, was conducted to determine the relationship between student scientific knowledge scores, beliefs and attitudes, and self-reported demographic information.

Analysis of the second survey was conducted and included descriptive statistics and nonparametric analyses to compare the relationship between multiple ranking questions. Analysis that included questions from both surveys included both descriptive statistics and parametric analyses, when appropriate, to compare students' science knowledge scores based on their sources and judgment of different information related to science.

\section{E. Participants}

Participants for the first part of the study included 12676 students who completed the Science Knowledge, Beliefs

TABLE III. Number of college science courses completed.

Number of college science courses completed (not including the one currently enrolled in)

\begin{tabular}{ll}
\hline 0 & $n=5038(40)$ \\
1 & $n=3765(30)$ \\
2 & $n=1959(16)$ \\
3 & $n=725(6)$ \\
4 & $n=319(3)$ \\
5 & $n=122(1)$ \\
6 or more & $n=547(4)$ \\
\hline
\end{tabular}

and Attitudes Survey between 1989 and 2016. Forty-nine percent of the survey respondents were female and $51 \%$ were male. Forty-seven percent of the survey respondents were freshman, $31 \%$ were sophomores, $12 \%$ were juniors, and $9 \%$ were seniors or super seniors (students in their 5th or later year of an undergraduate degree). Seventy percent of the survey respondents were taking their first or second college science course. Table III shows the breakdown of college science courses completed by the survey respondents.

Additionally, students were from a variety of majors, representing a majority of non-STEM majors. Table IV shows a breakdown of students' self-reported majors. Of those in science and engineering, over 50\% were enrolled in these courses as upper classmen (juniors, seniors, and "super" seniors), compared to less than $30 \%$ for other majors, suggesting that they were taking the class out of interest for the subject and not as a science requirement for their degree. The largest groups of students were business majors, students in social and behavioral sciences and students who were undecided in their major.

Participants who only completed the Interest and Sources of Information in Science Survey included 489 students, $50 \%$ male and $50 \%$ female. No information about their year in school was collected. Participants who completed both surveys, were a subset of those who completed the Science Knowledge, Beliefs and Attitudes Survey, and included 772 students. Forty-eight percent of the participants were female and $52 \%$ were male. Sixty-three percent of the survey

TABLE IV. Students' self-reported majors.

\begin{tabular}{lc}
\hline \hline Declared major & $\begin{array}{c}\text { Number of respondents } \\
n=12674(\% \text { of total) }\end{array}$ \\
\hline Undecided & $n=2078(16)$ \\
General studies & $n=82(0.7)$ \\
Science and engineering & $n=731(6)$ \\
Social and behavioral sciences & $n=2363(19)$ \\
Business and management & $n=3874(31)$ \\
Arts, writing & $n=1379(11)$ \\
Education & $n=729(6)$ \\
Architecture & $n=135(1)$ \\
Premed, nursing, public heath & $n=176(1)$ \\
History, language, and humanities & $n=1100(9)$ \\
\hline \hline
\end{tabular}


respondents were freshman, $24 \%$ were sophomores, $7 \%$ were juniors, and 5\% were seniors or super seniors (5th year in school).

\section{RESULTS}

\section{A. Context}

This work builds on prior studies of this population of introductory astronomy students [40-42]. Below we present and discuss results for each research question. To contextualize the findings, we summarize relevant results related to the overall data set.

Across the 27-year data set, students averaged about $79 \%($ Mean $=11.06$, S.D. $=2.23$, out of a possible 14 points) on the basic science knowledge questions. The full distribution of scores can be seen in Fig. 1. Additionally, there were some local variations in student average scores while looking across different years (Table V), although often higher scores are seen in years when there have been more STEM majors (e.g., 1991 and 1992 saw 30\% science and engineering majors compared to lower fractions of those majors in other years).

Students' open responses to the prompt "what does it mean to study something scientifically?" were also coded both thematically and for overall quality. In the overall sample, $72 \%$ of the responses were of sufficient quality to be coded and on target to the question. Of these 9160 responses, $21 \%$ of students discussed it as a way or thinking or perspective, $16 \%$ discussed it as a way of gaining knowledge, $26 \%$ described observation or experimentation, $10 \%$ talked about the scientific method, $11 \%$ talked about hypotheses or hypothesis testing, 9\% talked about data analysis, and $8 \%$ mentioned using evidence. These were the largest categories of codes found in the data. Additionally, students' responses were scored for complexity of response. Within the on-target responses, $16 \%$ were scored as a "1" indicating that students used correct words without linking ideas. Most responses, 70\%, were scored as a "2" demonstrating students' basic understanding of scientific study as well as more in-depth aspects, such as analysis or repetition. A smaller fraction (14\%) were scored

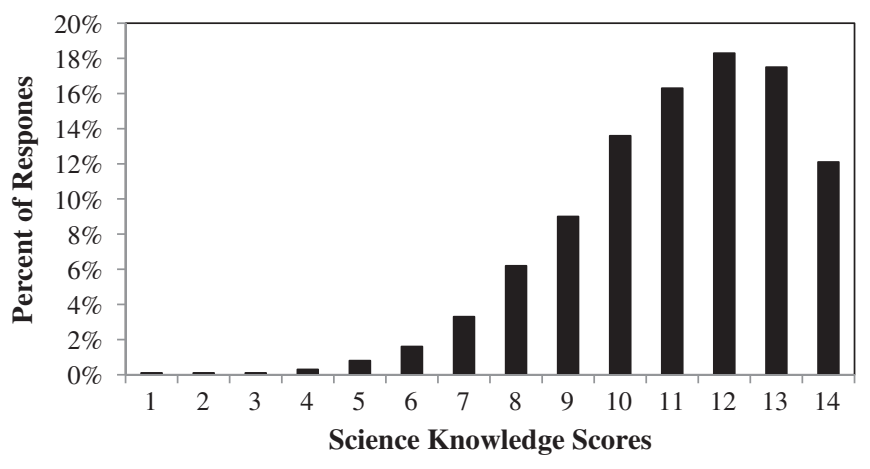

FIG. 1. Distribution of basic science knowledge scores $(n=12676)$.
TABLE V. Average science knowledge scores over time.

\begin{tabular}{lcc}
\hline \hline Year & Mean & S.D. \\
\hline $1989-1990(n=1854)$ & 10.7 & 2.3 \\
$1991-1992(n=420)$ & 12.0 & 1.8 \\
$1993-1994(n=184)$ & 11.1 & 1.9 \\
$1995-1996(n=605)$ & 10.7 & 2.3 \\
$1997-1998(n=887)$ & 10.6 & 2.2 \\
$1999-2000(n=357)$ & 10.9 & 2.2 \\
$2001-2002(n=835)$ & 11.3 & 2.3 \\
$2003-2004(n=639)$ & 10.9 & 2.3 \\
$2005-2006(n=1202)$ & 11.1 & 2.2 \\
$2007-2008(n=1960)$ & 11.0 & 2.4 \\
$2009-2010(n=1655)$ & 11.2 & 2.2 \\
$2011-2012(n=494)$ & 11.3 & 2.1 \\
$2013-2014(n=817)$ & 11.1 & 2.1 \\
$2015-2016(n=701)$ & 11.7 & 1.9 \\
\hline \hline
\end{tabular}

as either a " 3 " or " 4 " demonstrating a strong or exemplary (expertlike) response to the prompt.

\section{B. Results by research question}

\section{Research question 1}

How do introductory astronomy college students' responses to basic science knowledge questions compare to nationally reported responses?

Figure 2 compares our results for the nine science knowledge questions that have been consistently used by the NSB Science and Engineering Survey for the Public [23] and on our survey for the years between 1989 and 2016. The NSB reports aggregate data (usually every two years), so we binned our data to match the NSB reporting frequency, although there are a couple of gaps. Additionally, the data include results to questions recently used in two surveys by the Pew Research Center [24,25] that are also shared by the other two surveys. The full data table can be found in the Appendix, which includes more information about the number of surveys completed during each time interval on each survey.

It is important to note the difference in both the methodology of data collection and the populations for each data set. The NSB and Pew survey data were collected through phone surveys and included other types of questions, while our data were collected through a pen-andpaper survey in a classroom setting. In addition, the NSB and Pew sample included participants of different demographics from all over the United States, while our sample consisted of undergraduate students in introductory science courses at a single university.

In general, students from our undergraduate sample performed better overall on every question shared by all three surveys, by as much as $40 \%$ on a single question as compared to the NSB sample. Despite the higher percentage of correct responses by the overall undergraduate student sample, the trend in percent correct from 1989 


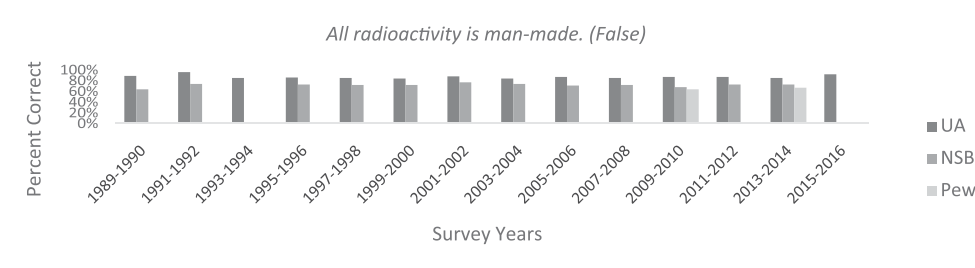

Lasers work by focusing sound waves. (False)

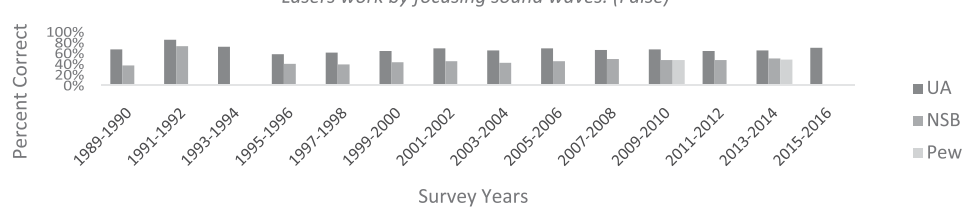

Electrons are smaller than atoms. (True)

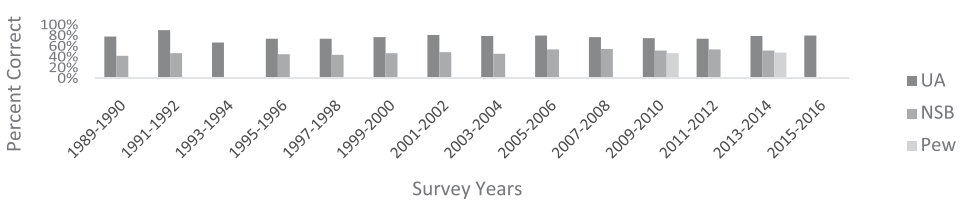

The universe began with a huge explosion. (True)
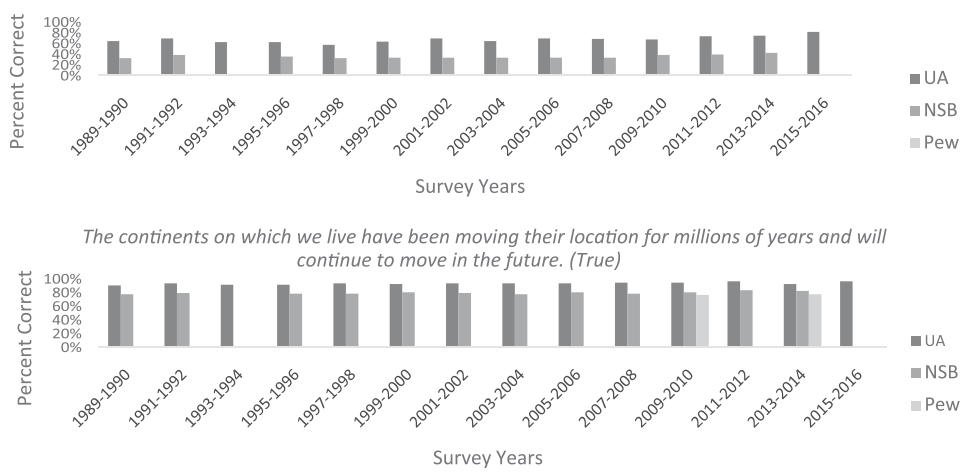

Does the Earth go around the Sun, or does the Sun go around the Earth? (Earth around Sun)

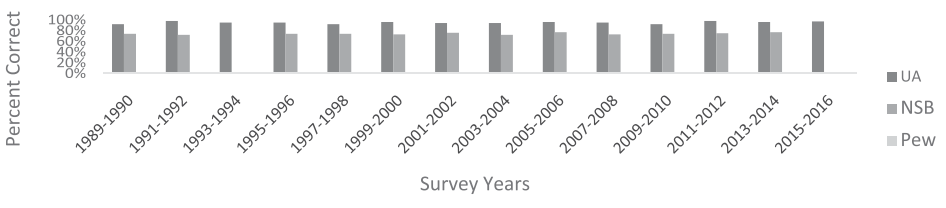

How long does it take for the Earth to go around the Sun? (One year)

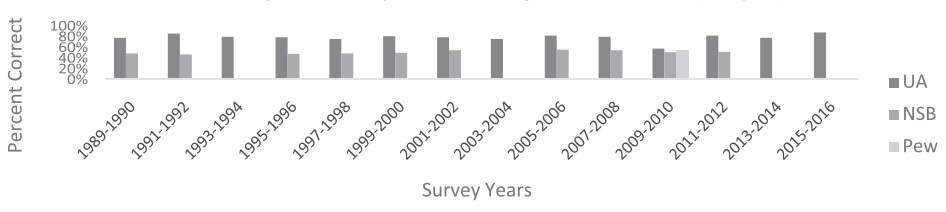

Antibiotics kill viruses as well as bacteria. (False)

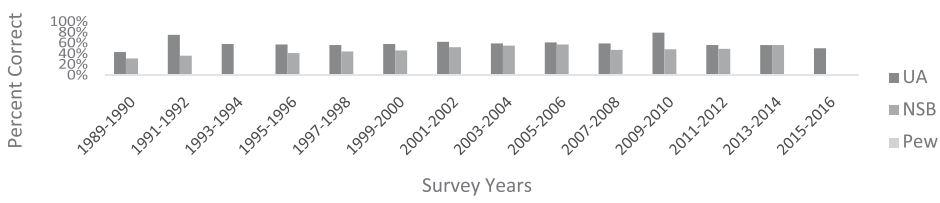

Human beings, as we know them today, developed from earlier species of animals. (True)

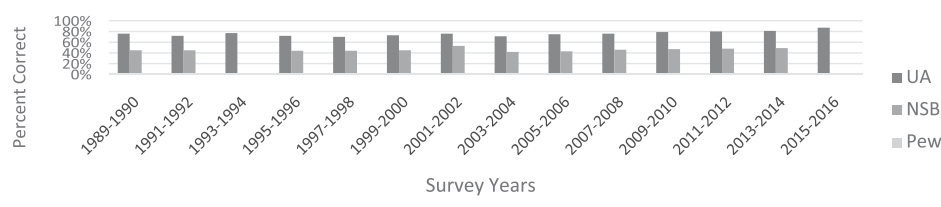

FIG. 2. Comparison of scores on common science knowledge questions on surveys from our sample of undergraduate students (UA), the surveys administered by the NSB, and the surveys administered by Pew Research Center (Pew). 
to 2016 is very similar to what the NSB reports. With the exception of one year (1991), results from eight of the nine questions are relatively stable from 1989 to 2016, similar in trend to the NSB results. The question that stands out is "Antibiotics kill viruses as well as bacteria." The NSB report shows that the percentage of the U.S. public who answered this question correctly rose from $30 \%$ in 1990 to $56 \%$ in 2006 and back down to $48 \%$ in 2012. Similarly, the percentage of our sample answering this item correctly rose from $42 \%$ correct in 1989 to around $60 \%$ after the year 2000 and back down to $49 \%$ in 2015-2016. The figure shows recent results from the Pew survey (light gray) that included five of the nine questions shared by the NSB survey. Students in our sample also outperformed the Pew sample on all questions that were given to all of the groups.

\section{Research question 2}

How are introductory astronomy students' characteristics, beliefs, and attitudes related to their science knowledge scores?

Students' self-reported demographic information was used to investigate relationships between their characteristics and their science knowledge scores. When broken down by reported major, shown in Table VI, physical science and engineering students performed the best overall. Among students who indicated that they were education majors $(n=724)$, the overall average number of questions correct was significantly lower $[t(12608)=6.83 \quad p<0.01]$, Mean $=10.5($ S.D. $=2.2)$ compared to all the noneducation majors $(n=11884)$ who answered an average Mean $=11.1$ $($ S.D. $=2.2)$ questions correctly. Additionally, education majors' average score was consistently lower than every other subgroup of majors. The effect size of these differences ranged from very small $(g=0.085)$ when compared to undecided majors to large $(g=0.895)$ when compared to physical science and math majors.

Females $(n=6208,49 \%)$ on average (Mean $=10.7$, S.D. 2.2) scored statistically significantly lower than men $(n=6386,51 \%)$ on average $($ Mean $=11.4$, S.D. $=2.2)$ on the science knowledge portion of the survey,

TABLE VI. Average science knowledge scores by major.

\begin{tabular}{lcc}
\hline \hline Major & Mean & S.D. \\
\hline Undecided $(n=2070)$ & 10.7 & 2.4 \\
Physical science, math $(n=499)$ & 12.4 & 2.0 \\
Biological, life sciences, health $(n=377)$ & 11.3 & 2.4 \\
Agriculture $(n=30)$ & 11.4 & 2.1 \\
Engineering $(n=260)$ & 12.2 & 1.7 \\
Social and behavioral sciences $(n=2346)$ & 11.2 & 2.2 \\
Business, management $(n=3851)$ & 11.0 & 2.2 \\
Arts, humanities, writing $(n=1375)$ & 11.3 & 2.2 \\
Education $(n=724)$ & 10.5 & 2.2 \\
Architecture $(n=134)$ & 11.4 & 2.0 \\
History, language, humanities $(n=1097)$ & 11.2 & 2.2 \\
\hline \hline
\end{tabular}

$t(12592)=20.14, p<0.01$. Over the 27 years of the study, the percentage of females and males ranged from the extremes of $40 \%$ females and $60 \%$ males to $59 \%$ females to $41 \%$ males, although these extremes only occurred in one quarter of the years of the study. During the other years of the study, the overall distribution of females and males in the study was between $45 \%$ and $55 \%$ of either gender. Females on average consistently scored lower than males on the science knowledge questions every year. The yearly average score for males ranged from 11.0 to 12.3 questions correct and the yearly average scores for females ranged from 10.0 to 11.6. The average male score was larger by 0.5 to 1.0 questions on the survey in any given year, the differences having small $(g=0.18)$ to medium $(g=0.5)$ effect sizes respectively.

Table VII shows the average science knowledge score based on students' year in college and Table VIII shows the averages science knowledge score based on number of college science courses completed. There were small significant positive linear trends in students' science knowledge score based on their year in school $[r(12610)=0.13$, $p<0.05$ ] and related to the number of college science courses completed $[r(12610)=0.17, p<0.05]$. There was a small positive, yet statistically, significant, correlation between students' self-reported GPA and their science knowledge score $[r(10231)=1.0, p<0.01]$.

To look for patterns between students' attitudes and beliefs and their science knowledge scores, participants with extreme scores for each attitude and belief factor were used. Scores for this analysis were only included if a student's mean factor score indicated that they agreed (had an average score of 4 and above) or disagreed (had an average score of 2 and below) with a given set of items. Students with a mean factor score of 4 (agree) or higher were compared with students with a mean factor score of 2 (disagree) or lower. The results are given in Table IX and differences between groups were tested using independent $t$ tests.

Statistically significant differences $\left.{ }^{*}\right)$ in science knowledge scores were detected for students with very high and very low mean scores for belief in aliens and life beyond earth $[t(3020)=2.66, p<0.01]$, with an average difference of 0.2 questions, faith-based beliefs $[t(2659)=18.8$, $p<0.001]$ with a mean difference of 1.5 questions, and belief in unscientific phenomena $[t(3434)=11.5$, $p<0.001$ ], a mean difference of 0.9 questions. There

TABLE VII. Average science knowledge score by year in school.

\begin{tabular}{lc}
\hline \hline Year in school & $\begin{array}{c}\text { Average science knowledge } \\
\text { score out of } 14\end{array}$ \\
\hline Freshman $(n=5963)$ & Mean $=10.9$, S.D. $=2.2$ \\
Sophomore $(n=3916)$ & Mean $=11.0$, S.D. $=2.2$ \\
Junior $(n=1526 n=1526)$ & Mean $=11.2$, S.D. $=2.2$ \\
Senior $(n=1073)$ & Mean $=11.9$, S.D. $=2.0$ \\
Super Senior $(n=101)$ & Mean $=12.5$, S.D. $=1.6$ \\
\hline \hline
\end{tabular}


TABLE VIII. Average science knowledge score by number of college science courses completed.

\begin{tabular}{llc}
\hline \hline $\begin{array}{l}\text { Number of college science } \\
\text { courses completed }(n=11539)\end{array}$ & $\begin{array}{c}\text { Mean science knowledge } \\
\text { score out of } 14\end{array}$ & $\begin{array}{c}\text { Percentage of } \\
\text { respondents }\end{array}$ \\
\hline 0 courses completed $(n=5007)$ & Mean $=10.8$, S.D. $=2.2$ & $40.0 \%$ \\
1 course completed $(n=3748)$ & Mean $=11.0$, S.D. $=2.2$ & $29.7 \%$ \\
2 courses completed $(n=1951)$ & Mean $=11.3$, S.D. $=2.1$ & $15.6 \%$ \\
3 courses completed $(n=722)$ & Mean $=11.6$, S.D. $=2.0$ & $5.6 \%$ \\
4 courses completed $(n=316)$ & Mean $=12.0$, S.D. $=2.0$ & $2.4 \%$ \\
5 courses completed $(n=135)$ & Mean $=12.1$, S.D. $=2.2$ & $1.0 \%$ \\
6 or more courses completed $(n=135)$ & Mean $=12.3$, S.D. $=1.8$ & $1.5 \%$ \\
\hline \hline
\end{tabular}

TABLE IX. Average science knowledge scores of students with average factor scores at or more extreme than "agree" or "disagree" for each category.

\begin{tabular}{lcc}
\hline \hline & $\begin{array}{c}\text { Agree } \geq 4 \\
\text { across factor } \\
\text { mean (S.D.) }\end{array}$ & $\begin{array}{c}\text { Disagree 2 } \leq \\
\text { across factor } \\
\text { mean (S.D.) }\end{array}$ \\
Factor or category & $11.2(2.2)$ & $11.0(2.2)$ \\
Belief in aliens and life & $n=2124$ & $n=898$ \\
beyond Earth* & $10.5(2.2)$ & $12.0(2.0)$ \\
Faith-based beliefs* & $n=1464$ & $n=1197$ \\
& $11.3(2.2)$ & $11.3(2.0)$ \\
Positive attitudes towards & $n=4174$ & $n=24$ \\
science and technology & $10.7(2.3)$ & $11.6(2.1)$ \\
Belief in unscientific & $n=1611$ & $n=1825$ \\
phenomena* & & \\
\hline \hline
\end{tabular}

were no significant differences found in science knowledge scores for students with very high and low scores for the positive attitudes towards science and technology.

A multiple regression was used to investigate the relative contribution each variable had on students' science knowledge scores. This analysis revealed that taken together, the demographic variables accounted for only $7.4 \%$ of the variance in students' scores $[F(5,10706)=170.4$, $\left.p<0.001, R^{2}=0.074\right]$. The regression also revealed a large amount of multicollinearity between the demographic variables, most notably between a student's year in school and the number of university science courses completed. The strongest predictor of a student's score on the overall science knowledge questions was how many science courses they had completed, which is not surprising, but only accounted for $4 \%$ of the variance explained in their science knowledge scores. Additionally, students' beliefs and attitudes accounted for 5\% of the variance in their science knowledge scores $[F(4,10946)=147.0$, $\left.p<0.001, R^{2}=0.051\right]$. Taken together, students' selfreported demographic variables and beliefs and attitudes accounted for $11 \%$ of the variance in their science knowledge scores $\left[F(9,9312)=131.8, p<0.001, R^{2}=0.113\right]$.

\section{Research question 3}

What is the relationship between introductory astronomy students' interest in science, their career plans, and how useful they believe science will be to their future career?
Data for this question was taken from students who completed Interest and Sources of Information in Science Survey. Students' self-reported interest in science and astronomy as well as knowledge of science was analyzed using descriptive statistics and Spearman ranked correlations. Students' overall interest in science and astronomy are shown in Fig. 3 and Fig. 4 below.

Students' interest in science in general and interest in astronomy showed a positive significant correlation $\left(r_{s}=0.573, p<0.01\right)$. Twenty-four percent of the respondents reported that they were very interested in both science in general and astronomy. Fourteen percent of the students reported very high interest in astronomy and lower interest in science and general and $37 \%$ of students reported a very

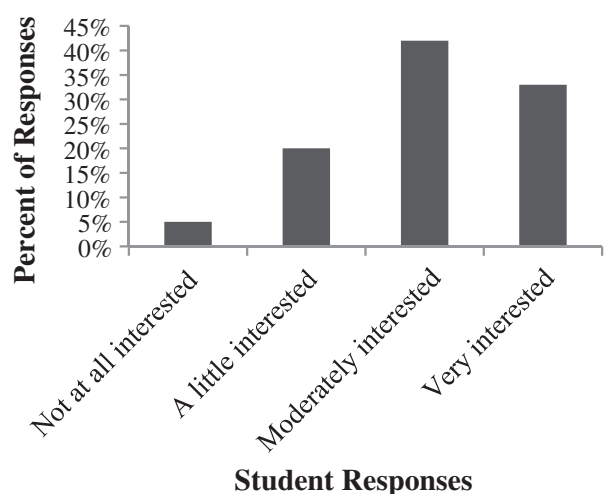

FIG. 3. Self-reported interest in science.

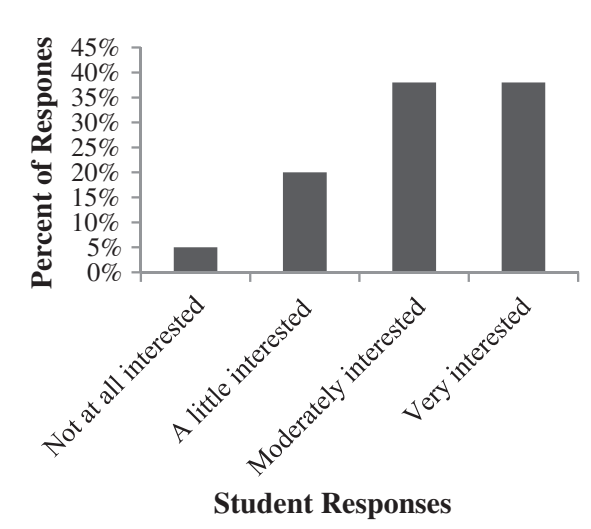

FIG. 4. Self-reported interest in astronomy. 


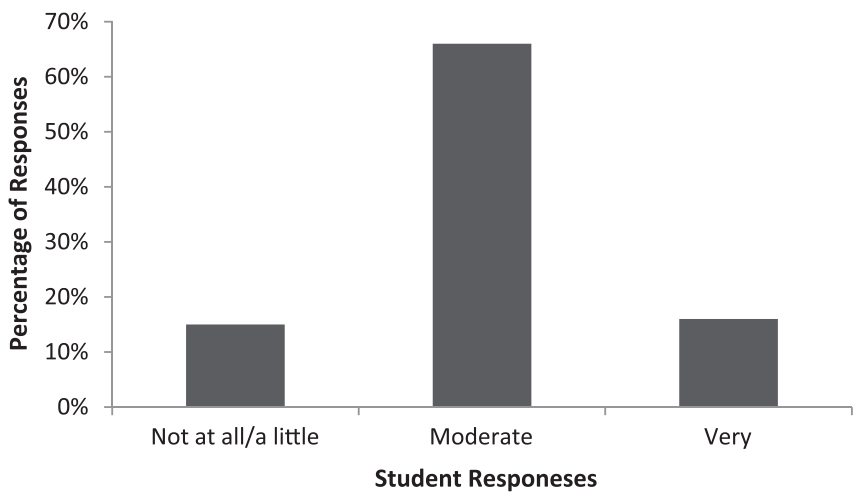

FIG. 5. Students' self-reported knowledge about science.

high interest in science in general and lower interest in astronomy specifically. Additionally, students were asked to rank their overall knowledge about science from not at all to a little to very knowledgeable. As can be seen in Fig. 5, most students rated themselves as moderately knowledgeable about science.

Students' interest in science and self-reported knowledge in science showed a moderate positive significant correlation $\left(r_{s}=0.474, p<0.01\right)$. Over $75 \%$ of those who reported being very knowledgeable were also very interested in science and $60 \%$ of those who reported being not at all knowledgeable also reported low interest in science. Seven hundred and sixty of these students also completed the Science Knowledge, Beliefs and Attitudes Survey and were used to compare their self-reported knowledge about science and their basic science knowledge. The average science knowledge score of this subsample was 10.7, S.D. $=1.9$. There was a small significant positive correlation between students' self-reported knowledge and their basic knowledge scores $\left(r_{b}=0.181, p<0.001\right)$. The students who reported that they were moderately knowledgeable and very knowledgeable receive the highest basic science knowledge scores.

Additionally, there was a significant positive correlation between those who reported that they liked science and felt that science was important to their future career, $\left(r_{s}=0.456\right.$, $p<0.01)$. Students' self-reported majors and careers plans were coded into general categories (e.g., undecided, STEM, business, retail, public service education, arts and humanities, and law) for analysis. Table $\mathrm{X}$ gives the breakdown of students' career choices in the sample and the percentage of those who believed that science was both very and not at all important to their future careers.

Overall, students' interest in science was significantly different depending on their future career choices. $\left[X^{2}(48)=182, p<0.01\right]$ with STEM majors showing the most interest in science and students planning to go into careers in retail and service reporting the least interest in science. Those who were undecided about their future career choices were split between being very interested and uninterested in science, although twice as many felt that science would not be important to their future career. Those planning on going into education, most as elementary school teachers, were split but still twice as many felt that science was not at all relevant to their future career.

\section{Research question 4}

What is the relationship between students' sources for science information and their science knowledge?

On the Science Knowledge, Beliefs and Attitudes Survey, students were asked to rate the top three places they gained information about science both for their own knowledge and for class assignments. Students' responses to sources of information about science were analyzed using descriptive statistics. Figure 6 below shows students' responses based on the most frequent responses.

Students consistently reported gaining a large percentage of information for both their own knowledge and their course assignments from internet searches. Unsurprisingly, they also reported gaining information from professors and textbooks for course assignments, with fewer reported these sources for their own knowledge. Online science sites were also important for these students gaining knowledge about science and Wikipedia was an important source of information for a small fraction of these students.

TABLE X. The relationship between students' future plans and the importance of science to their future career.

\begin{tabular}{lcc}
\hline \hline $\begin{array}{l}\text { Students reported future } \\
\text { careers }(n=1211)\end{array}$ & $\begin{array}{c}\text { \% of respondents who indicated } \\
\text { that science is very important to } \\
\text { their future career }\end{array}$ & $\begin{array}{c}\text { \% of respondents who indicated } \\
\text { that science is not at all important } \\
\text { to their future career }\end{array}$ \\
\hline Undecided $(n=209)$ & 18 & 47 \\
STEM $(n=170)$ & 75 & 6 \\
Business $(n=317)$ & 11 & 55 \\
Retail or service $(n=24)$ & 0 & 83 \\
Public service $(n=137)$ & 17 & 39 \\
Education $(n=78)$ & 18 & 42 \\
Arts and humanities & 6 & 69 \\
$\quad(n=160)$ & & 75 \\
Law $(n=75)$ & 7 & 75 \\
\hline \hline
\end{tabular}




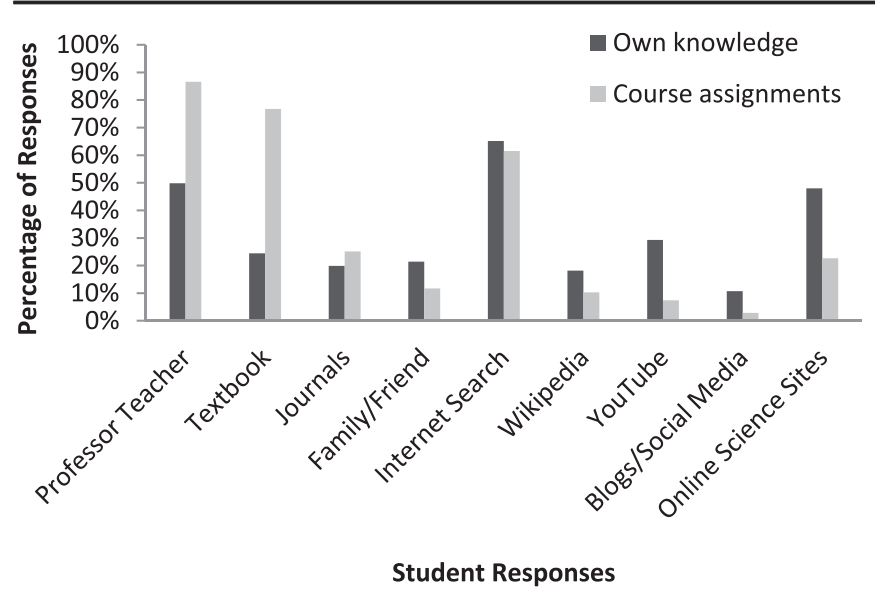

FIG. 6. Top sources where students report getting information about science.

Analyses, both descriptive counting and nonparametric statistical tests of relationships, revealed that there was no pattern between where students reported getting their information about science and their science knowledge scores, use of evidence, or complexity scores when describing what it means to study something scientifically.

\section{Research question 5}

What are the relationships between introductory astronomy students' judgments of the reliability of sources of information and their science knowledge?

Students were asked to rank their top three choices for the most reliable sources of scientific information as well as the least reliable sources of scientific information. Responses to both rankings were analyzed for consistency to support students' rankings of reliable sources. We found $98 \%$ of the respondents were consistent in their ratings and those were included in the analysis shown in Fig. 7. Overall, taking into

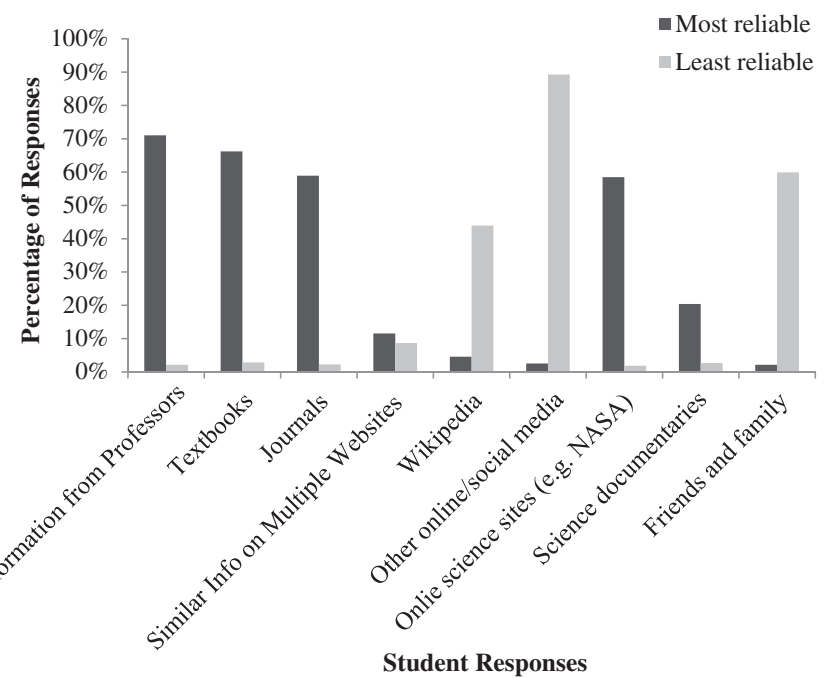

FIG. 7. Students' top choices about the most and least reliable sources of science information. account students' top choices, students reported that the most reliable sources of scientific information were professors or teachers (71\%), textbooks (66\%), academic journal (researchers) (59\%), and online science sites (e.g., NASA) (59\%). Fewer students ranked finding similar information from multiple websites (12\%), Wikipedia $(5 \%)$, or social media sites $(3 \%)$ as being the most reliable sources of scientific information. Social media (89\%), friends and family member $(60 \%)$, and Wikipedia (43\%) were reported as the least reliable sources of science information.

For the subset of students who fully completed both surveys $(n=760)$, each student had a knowledge score as well as a quality and thematic description of how they described studying something scientifically. Students' science knowledge scores ranged from $29 \%$ to $100 \%$ with an average of $76 \%$. This range is slightly lower, but overall consistent, with our larger sample of students reported above. In their open-ended responses, $22 \%$ of students described science as empirical, having to do with observations or data, $14 \%$ described the use of hypotheses, $10 \%$ described the use of evidence, and $10 \%$ described the use of data or analysis. Students' complexity scores ranged $20 \%$ of the respondents scored as a "0" (off target responses) to one individual who was scored as a "4" (exemplary response). One-third of the respondents had an answer that was scored as a "2" (on-target with small meaningful connections) and $37 \%$ had an answer that was scored as a "1" (on-target but superficial).

To investigate how students' responses about reliability of sources were connected to their science knowledge scores, students' responses were binned into categories including academic sources (lectures, professors, textbooks, assigned readings), online searching (Wikipedia, Google searches), social media (Facebook, YouTube), online science sites (e.g., NASA, Discovery), and other types of media (books, TV, and newspapers). A comparison was then made between how students rated different sources of information to their science knowledge scores. There was a significant difference $[t(631)=4.73, p<0.01]$, with a medium effect size $(g=0.65)$, in students' science knowledge scores between those who reported similar information on multiple websites and Wikipedia as top sources of reliable information about science $($ Mean $=9.7$, S.D. $=2.1)$ versus more academic sources such as journals and textbooks as more reliable sources of information $($ Mean $=10.9$, S.D. $=1.7$ ). Additionally, students who reported online sources as more reliable were less likely to discuss evidence and hypothesis testing in their open-ended responses about science and had lower complexity scores to their responses about what it means to study something scientifically.

\section{DISCUSSION}

Our work over the last 27 years has given us insight into introductory astronomy students' basic science knowledge, beliefs, and attitudes. More recently, we have examined 
students' interest in science, self-reported sources of information about science and how they value that information and the relationships between these and students' science knowledge. The longevity of our study has helped us look for long term trends and boosted our confidence in our findings. Similar to what has been reported about the U.S. general public's level of factual knowledge about science [23] very little has changed in students' basic science knowledge over the course of the study and there is evidence that more college science courses are associated with more correct factual answers [14]. Our results support Miller's [49] conclusion that college science courses are important for increases in science knowledge. There was a small linear trend between students' science knowledge scores and their year in college. Despite this, it is not clear if science courses are the largest contributor to students' basic science knowledge or if it is attributable to other factors as they progress through their college career. Additionally, based on the finding that students in this study outperformed the results of the general public, it seems that being prepared for, and college bound, may be a better predictor of basic science knowledge and not the courses themselves. In our data, it is clear that there are other intervening factors that have a much larger effect than number of science courses completed, reported majors, or other student demographic variables. This lack of explanatory power is also supported by literature on lifelong and free-choice learning, which supports the claim that most science learning is done outside of school [50,51].

The belief and attitude items on the survey are relevant to an instructor of introductory astronomy for nonscience majors since they combine to form a landscape of beliefs and attitudes toward science and technology. Instructors need to know about their students' prior knowledge and beliefs and the level of susceptibility they might have to pseudoscience and irrational belief systems. One factor from the analysis is directly relevant to one of the most exciting topics in astronomy: the search for life in the Universe, or astrobiology. The questions included those that probed students' belief in intelligent life beyond Earth and their support of the search for life on other planets. Similar to other studies of students attitudes toward science [26,27], students' positive attitudes towards science and technology were seen across the spectrum of students who had higher and lower science knowledge scores showing that strong science knowledge is not required for support for science. This was in contrast to students who had strong religious beliefs and pseudoscientific beliefs. They had worse science knowledge scores than those who did not hold these beliefs.

This study provides empirical evidence that students who have higher interest in science also perform better on basic science knowledge questions. Although unsurprising, this underscores the importance of these introductory astronomy courses as opportunities to engage students in science and increase their interest and motivation to learn about science. Additionally, many of the students in this study did not view science as important to their future career, yet as citizens it is important that they are able to make informed decisions about science that impact society and their own lives. This broader goal also aligns with the international goal of increasing scientific literacy for these students [6,20] and demonstrates further potential for introductory astronomy instructors to address the broader importance of science to society.

This study provides additional evidence that students are looking for much of their information about science online. This finding is similar to recent studies of high school students who report using the internet and search engines to conduct research $[15,52]$ and surveys of where the general public reports getting knowledge about science [23]. In this study, the sources of science information a student used did not predict a students' basic science knowledge but their ability to judge the reliability of information did seem to matter. This again aligns with findings from a study of high school students in which the trustworthiness was based on the perceived reliability of the source and not evaluation of the content [15]. The small population of students who believed that online sources were very reliable have yielded interesting insights into students' misunderstanding of science (e.g., replication or finding information on more than one website) which has been documented among high school students [52]. This provides evidence of a link between information literacy and scientific literacy supporting many instructors' intuition about this connection and other work describing this connection [9,17]. Our findings suggest that students' overall knowledge of science and how science works is more closely related to their ability to judge the reliability of sources of science information than their choice of sources of information. This is important for instructors to be aware of as they prepare to teach large populations of students who do not intend to go into science careers nor see science as integral to their future career and lives.

\section{A. Limitations}

There are several limitations to this study worth noting. The sample used for both surveys was one of convenience which allowed us to obtain responses from a large number of students in astronomy courses each year. As such, we are not able to generalize our findings to a larger sample, but this study may still be useful for understanding college students in nonmajor science classes with similar demographics at large public research universities. Although the first survey remained unchanged for over 25 years, giving us the ability to directly compare student response to the same questions, the items lacked depth beyond basic science knowledge making it difficult to make larger claim about students' scientific literacy. Thus, we have made our inferences carefully relying on the relationships between 
science knowledge, interest, attitudes and beliefs, demographic information, and self-reported sources of information. Additionally, our methods allowed for surveying students at a single point in time which did not allow for following students to note changes over their college career. Despite these limitations, the large amount of data that has demonstrated consistent results over time lends itself to our findings.

\section{CONCLUSION}

Overall, this study has provided valuable information about college students who choose to take nonmajor astronomy courses to better understand their basic science knowledge, attitudes towards science, interest in science, where they report getting their information about science, and their judgment of that information. The relationships between these demonstrate the value of helping students see the value of science in society, increasing their belief for the need for science, and helping them evaluate where they get their information about science. Although this was not an intervention study, it was clear that students with more positive attitudes and interest in science also had higher basic science knowledge and better information literacy. This supports the notion that introductory astronomy courses are opportunities to increase students' positive attitudes towards and the importance of science in their everyday lives as well as increase their ability to obtain and evaluate scientific information [2].

\section{ACKNOWLEDGMENTS}

This material is based upon work supported by the National Science Foundation under Grant No. 1244799. Any opinions, findings, and conclusions or recommendations expressed in this material are those of the authors and do not necessarily reflect the views of the National Science Foundation. We thank instructors who let us recruit from their courses and the tens of thousands of students who completed the surveys. We also thank our anonymous reviewers for their helpful critiques.

\section{APPENDIX: COMPARISON OF BASIC SCIENCE KNOWLEDGE QUESTION RESPONSES}

Results to science knowledge questions from our undergraduate sample (italicized), the NSB reports [23] (bold), and the Pew reports [11,12] underlined). N/A indicates that the question was not given on that survey that year.

TABLE XI.

\begin{tabular}{|c|c|c|c|c|c|c|c|c|c|c|c|c|c|c|c|c|c|c|c|c|c|c|c|c|c|c|c|c|}
\hline & $\begin{array}{l}\stackrel{2}{\alpha} \\
\text { à } \\
\text { à } \\
2\end{array}$ & ğ & $\frac{\tilde{a}}{\frac{1}{a}}$ & ू̆ & $\begin{array}{c}a \\
\frac{a}{a} \\
a \\
a\end{array}$ & ஜू & 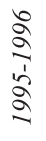 & $\hat{\sigma}$ & $\frac{\infty}{a}$ & 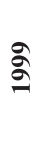 & 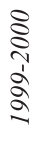 & હे & 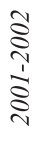 & 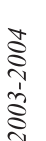 & ষ্ণ & 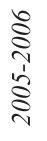 & 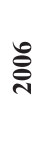 & 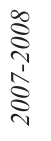 & $\stackrel{\infty}{\stackrel{\text { }}{1}}$ & 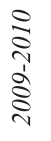 & ఫे| & 륭 & 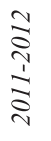 & ำ & $\stackrel{m}{\stackrel{2}{0}}$ & 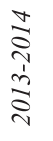 & $\stackrel{\nabla}{\overline{0}}$ & 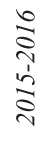 \\
\hline Question & \begin{tabular}{l}
\multirow{7}{*}{} \\
$\infty$ \\
$\prod_{\Sigma}$ \\
$\Sigma$
\end{tabular} & 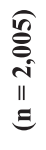 & 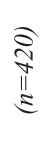 & 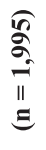 & 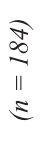 & $\begin{array}{l}6 \\
8 \\
0 \\
\text { i } \\
\text { ప }\end{array}$ & 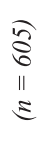 & 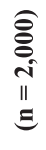 & $\begin{array}{l}\widehat{\infty} \\
\infty \\
\| \\
\Sigma\end{array}$ & 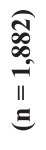 & 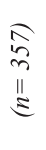 & 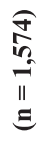 & $\begin{array}{l}\sqrt{2} \\
\infty \\
\| \\
\Sigma\end{array}$ & 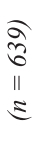 & 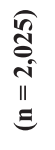 & 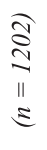 & 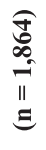 & $\begin{array}{l}20 \\
\stackrel{2}{2} \\
11 \\
=\end{array}$ & 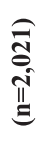 & $\begin{array}{l}\sqrt[6]{2} \\
\frac{6}{2} \\
11 \\
5\end{array}$ & $\begin{array}{c}\text { กิ } \\
8 \\
11 \\
\Xi\end{array}$ & $\underset{\widetilde{\sigma}}{\widetilde{\sigma}}$ & 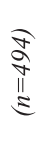 & 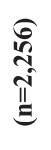 & $\begin{array}{l}6 \\
8 \\
8 \\
\text { II } \\
\qquad\end{array}$ & 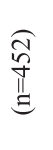 & 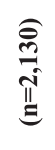 & 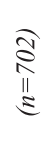 \\
\hline All radioactivity is man-made. (False) & 88 & 63 & 95 & 73 & 84 & 72 & 85 & 71 & 84 & 71 & 83 & 76 & 87 & 83 & 73 & 86 & 70 & 84 & 71 & 86 & 63 & 67 & 86 & 72 & $\underline{66}$ & 84 & 72 & 91 \\
\hline $\begin{array}{l}\text { Lasers work by focusing sound waves. } \\
\text { (False) }\end{array}$ & 67 & 37 & 85 & 37 & 72 & 40 & 58 & 39 & 61 & 43 & 64 & 45 & 69 & 65 & 42 & 69 & 45 & 66 & 49 & 67 & 47 & 47 & 64 & 47 & $\underline{48}$ & 65 & 50 & 70 \\
\hline Electrons are smaller than atoms. (True) & 77 & 41 & 89 & 46 & 66 & 44 & 73 & 43 & 73 & 46 & 76 & 48 & 80 & 78 & 45 & 79 & 53 & 76 & 54 & 74 & $\underline{46}$ & 51 & 73 & 53 & $\underline{47}$ & 78 & 51 & 79 \\
\hline $\begin{array}{l}\text { The universe began with a huge explosion. } \\
\text { (True) }\end{array}$ & 64 & 32 & 69 & 38 & 62 & 35 & 62 & 32 & 57 & 33 & 63 & 33 & 69 & 64 & $33^{\mathrm{a}}$ & 69 & 33 & 68 & 33 & 67 & $\underline{\mathrm{NA}}$ & 38 & 73 & $39^{b}$ & $\underline{\mathrm{NA}}$ & 74 & 42 & 81 \\
\hline $\begin{array}{l}\text { The continents on which we live have been } \\
\text { moving their location for millions of years } \\
\text { and will continue to move in the future. } \\
\text { (True) }\end{array}$ & 90 & 77 & 93 & 79 & 91 & 78 & 91 & 78 & 93 & 80 & 92 & 79 & 93 & 93 & 77 & 93 & 80 & 94 & 78 & 94 & $\underline{76}$ & 80 & 96 & 83 & $\underline{77}$ & 92 & 82 & 96 \\
\hline $\begin{array}{l}\text { Does the Earth go around the Sun, or does } \\
\text { the Sun go around the Earth? (Earth around } \\
\text { Sun) }\end{array}$ & 91 & 73 & 97 & 71 & 94 & 73 & 94 & 73 & 91 & 72 & 95 & 75 & 93 & 93 & 71 & 95 & 76 & 94 & 72 & 91 & $\underline{\mathrm{NA}}$ & 73 & 97 & 74 & $\underline{\mathrm{NA}}$ & 95 & 76 & 96 \\
\hline $\begin{array}{l}\text { How long does it take for the Earth to go } \\
\text { around the Sun? (One year) }\end{array}$ & 77 & 48 & 85 & 46 & 79 & 47 & 78 & 48 & 75 & 49 & 80 & 54 & 78 & 75 & $\mathbf{N A}$ & 81 & 55 & 79 & 54 & 57 & $\underline{54}$ & 50 & 81 & 51 & $\underline{\mathrm{NA}}$ & 77 & NA & 87 \\
\hline $\begin{array}{l}\text { Antibiotics kill viruses as well as bacteria. } \\
\text { (False) }\end{array}$ & 42 & 30 & 74 & 35 & 57 & 40 & 56 & 43 & 55 & 45 & 57 & 51 & 61 & 58 & 54 & 60 & 56 & 58 & 46 & 78 & NA & 47 & 55 & 48 & $\underline{\mathrm{NA}}$ & 55 & 55 & 49 \\
\hline $\begin{array}{l}\text { Human beings, as we know them today, } \\
\text { developed from earlier species of animals. } \\
\text { (True) }\end{array}$ & 76 & 45 & 72 & 45 & 77 & 44 & 72 & 44 & 70 & 45 & 73 & 53 & 76 & 71 & $42^{\mathrm{a}}$ & 75 & 43 & 76 & 46 & 79 & NA & 47 & 80 & $48^{b}$ & $\underline{\text { NA }}$ & 81 & 49 & 87 \\
\hline
\end{tabular}

${ }^{\mathrm{a}}$ Question asked of 1,558 participants. ${ }^{\mathrm{b}}$ Question asked of 1544 participants. 
[1] A. Fraknoi, The State of Astronomy Education in the US, in Astronomy Education: Current Developments, Future Coordination, edited by J. A. Percy (Astronomical Society of the Pacific, San Francisco, 1996).

[2] B. Partridge and G. Greenstein, Goals for "Astro 101:" Report on workshops for department leaders, Astron. Educ. Rev. 2, 46 (2004).

[3] N. Kober, Reaching students: What Research Says About Effective Instruction in Undergraduate Science and Engineering (National Academies Press, Washington, DC, 2015), DOI:10.17226/18687.

[4] R. Millar and J. Osborne, Beyond 2000: Science Education for the Future (King's College London, School of Education, London, 1998).

[5] G. E. DeBoer, Scientific literacy: Another look at its historical and contemporary meanings and its relationship to science education reform, J. Res. Sci. Teach. 37, 582 (2000).

[6] D. A. Roberts and R. W. Bybee, Scientific literacy, science literacy, and science education, in Handbook of Research on Science Education, edited by N. G. Lederman and S. K. Abell (Routledge, New York and London, 2014), Vol. II.

[7] F. J. Rutherford and A. Ahlgren, Science for all Americans (Oxford University Press, Oxford, 1991).

[8] NGSS Lead States, Next Generation Science Standards: For States, by States (The National Academies Press, Washington, DC, 2013).

[9] J. A. Porter, K. C. Wolbach, C. B. Purzycki, L. A. Bowman, E. Agbada, and A. M. Mostrom, Integration of information and scientific literacy: Promoting literacy in undergraduates, CBE Life Sci. Educ. 9, 536 (2010).

[10] J. Maienschein, Commentary: To the future-arguments for scientific literacy, Science communication 21, 75 (1999).

[11] J. Dillon, On scientific literacy and curriculum reform, Int. J. Environ. Sci. Educ. 4, 201 (2009).

[12] R. Millar, Twenty first century science: Insights from the design and implementation of a scientific literacy approach in school science, Int. J. Sci. Educ. 28, 1499 (2006).

[13] J. D. Miller, The measurement of civic scientific literacy, Publ. Understand. Sci. 7, 203 (1998).

[14] J. D. Miller, Public understanding of, and attitudes toward, scientific research: What we know and what we need to know, Publ. Understand. Sci. 13, 273 (2004).

[15] H. Julien and S. Barker, How high-school students find and evaluate scientific information: A basis for information literacy skills development, Library Inf. Sci. 31, 12 (2009).

[16] P. Brickman, C. Gormally, G. Francom, S. E. Jardeleza, V. G. Schutte, C. Jordan, and L. Kanizay, Media-savvy scientific literacy: Developing critical evaluation skills by investigating scientific claims, Am. Biol. Teach. 74, 374 (2012).

[17] C. Majetic and C. Pellegrino, When science and information literacy meet: An approach to exploring the sources of science news with non-science majors, Coll. Teach. 62, 107 (2014).

[18] D. A. Roberts, Scientific literacy/science literacy, in Handbook of Research on Science Education, edited by N. G. Lederman and S. K. Abell (Routledge, New York and London, 2007), Vol. I.
[19] A. Schleicher, Measuring Student Knowledge and Skills: A New Framework for Assessment (Organisation for Economic Co-Operation and Development, Paris, 1999).

[20] O. E. C. D., Draft Science Framework (Organisation for Economic Co-Operation and Development, Paris, 2015).

[21] A. L. Rudolph, E. E. Prather, G. Brissenden, D. Consiglio, and V. Gonzaga, A national study assessing the teaching and learning of introductory astronomy part II: The connection between student demographics and learning, Astron. Educ. Rev. 9, 1 (2010).

[22] R. C. Davis, The Public Impact of Science in the Mass Media (University of Michigan Survey Research Center, Ann Arbor, 1958).

[23] National Science Board, Science and Engineering Indicators 2016 (National Science Foundation, Arlington, 2016), http://www.nsf.gov/statistics/seind16.

[24] Pew Research Center for People, and the Press. Scientific achievements less prominent than a decade ago: Public praises science; scientists fault public, media. http://people press.org/report/528/ (2009).

[25] T. Monmaney, Educating Americans for the 21st century: How much do Americans know about science? Smithsonian magazine, http://www.smithsonianmag.com/ innovation/how-much-do-americans-know-about-science27747364/ (2013).

[26] R. Bybee and B. McCrae, Scientific literacy and student attitudes: Perspectives from PISA 2006 science, Int. J. Sci. Educ. 33, 7 (2011).

[27] C. Shen and H. P. Tam, The paradoxical relationship between student achievement and self-perception: a cross-national analysis based on three waves of TIMSS data, Educ. Res. Eval. 14, 87 (2008).

[28] N. Allum, P. Sturgis, D. Tabourazi, and I. Brunton-Smith, Science knowledge and attitudes across cultures: a metaanalysis, Publ. Understand. Sci. 17, 35 (2008).

[29] J. Trefil and R. M. Hazen, Scientific literacy: A modest proposal, in Science and the Educated American: A Core Component of Liberal Education, edited by J. Meinwald and J.G. Hildebrand (American Academy of Arts and Sciences, Cambridge, 2010).

[30] E. Pain, Teaching science to nonscience majors, Science careers, http://www.sciencemag.org/careers/2010/ 04/teaching-science-nonscience-majors (2010).

[31] D. Reed and M. Lyford, Science courses for nonscience majors: How much impact can one class make?, Bull. Am. Meteorol. Soc. 95, 1209 (2014).

[32] C. Impey, Science education in the age of science, in Science, and the Educated American: A Core Component of Liberal Education, edited by J. Meinwald and J. G. Hildebrand (American Academy of Arts and Sciences, Cambridge, 2010).

[33] S. P. Norris and L. M. Phillips, How literacy in its fundamental sense is central to scientific literacy, Sci. Educ. 87, 224 (2003).

[34] J. Nbina and B. J. Obomanu, The meaning of scientific literacy: A model of relevance in science education, Academic Leadership J. 8, 70 (2010).

[35] R. C. Laugksch and P. E. Spargo, Construction of a paperand-pencil Test of Basic Scientific Literacy based on selected literacy goals recommended by the American 
Association for the Advancement of Science, Publ. Understand. Sci. 5, 331 (1996).

[36] C. Gormally, P. Brickman, and M. Lutz, Developing a test of scientific literacy skills (TOSLS): Measuring undergraduates' evaluation of scientific information and arguments, CBE Life Sci. Educ. 11, 364 (2012).

[37] T. Rhodes, Assessing Outcomes and Improving Achievement: Tips and Tools for Using the Rubrics (Association of American Colleges and Universities, Washington, DC, 2010), https://www.aacu.org/value/rubrics/information-literacy.

[38] L. Thompson and L. A. Blankinship, Teaching information literacy skills to sophomore-level biology majors, J. Microbiol. Biol. Educ. 16, 129 (2015).

[39] A. F. Savage and B. A. Jude, Starting small: using microbiology to foster scientific literacy, Trends Microbiol. 22, 365 (2014).

[40] C. Impey, S. Buxner, J. Antonellis, E. Johnson, and K. Courtney, A twenty-year survey of science literacy among college undergraduates, J. Coll. Sci. Teach. 40, 4 (2011).

[41] H. Sugarman, C. Impey, S. Buxner, and J. Antonellis, Astrology beliefs among undergraduate students, Astron. Educ. Rev. 10, 010101 (2011).

[42] C. D. Impey, M. Formanek, S. R. Buxner, and M. C. Wenger, Twenty seven years of tracking undergraduate science knowledge and beliefs, Electron. J. Sci. Educ. 21, 4 (2017).

[43] University of Arizona Fact Book, http://factbook.arizona .edu/ (2016).
[44] National Science Board (NSB), Science \& Engineering Indicators (National Science Board, Washington, DC, 1987).

[45] J. D. Miller, Communicating Science to the Public (Wiley, London, 1987).

[46] P. Kline, An Easy Guide to Factor Analysis (Routledge, New York and London, 2014).

[47] National Science Board, Science and Engineering Indicators 2010 (NSF, Washington, DC, 2010).

[48] N. G. Lederman, F. Abd-El-Khalick, R. L. Bell, and R. S. Schwartz, Views of nature of science questionnaire: Toward valid and meaningful assessment of learners' conceptions of nature of science, J. Res. Sci. Teach. 39, 497 (2002).

[49] J. D. Miller, The impact of college science courses for nonscience majors on adult scientific literacy, $A A A S$ Conference Paper (2007).

[50] J. H. Falk and L. D. Dierking, The 95 percent solution, Am. Sci. 98, 486 (2010).

[51] J. H. Falk, M. Storksdieck, and L. D. Dierking, Investigating public science interest and understanding: evidence for the importance of free-choice learning, Publ. Understand. Sci. 16, 455 (2007).

[52] K. Purcell, L. Rainie, A. Heaps, J. Buchanan, L. Friedrich, A. Jacklin, C. Chen, and K. Zickuhr, How teens do research in the digital world, Pew Research Center, http://www.pewinternet.org/2012/11/01/how-teens-doresearch-in-the-digital-world/ (2012). 